\title{
Resources Integration Mechanism and Platform Construction of Hebei Scientific Small Micro-enterprise Siyun Xu, Mengxi Yang
}

Hebei Finance University, Baoding, Hebei, 071051, China

Key Words: scientific small micro-enterprise; resources integration; platform; construction

\begin{abstract}
This paper small micro-enterprise of science as study object, regarding its as beings together composed of factors mutually functioned and affected, so further discusses how to realize sustainable growth of enterprise as mainline by analyzing influence factors of enterprise growth and internal effect of different factors, it constructs growth motivation (entrepreneur), growth ability(technology innovation), resources base(financing ability(internal), innovative network(external), opportunity base(policy environment, financial ecology). It can reasonable enhance proportion of short-term loan in the overall credit resources and turn over credit structure by demonstration analysis, which makes it conform to financing demand of small micro-enterprise, change structure so that currency resource flowing to small micro-enterprise to automatically increase, which is the fundamental strategy of improving financing state of small micro-enterprise.
\end{abstract}

\section{Introduction}

Small and medium-sized enterprises are the important parts of national economy, up to the end of 2014, their scale registered in industrial and commercial departments of China reaches 42 millions, which is in excess of 99\%[1,2] of all the total number of enterprises in China. Meanwhile, they have contributed to half of GDP to economic growth for national economic growth, export of over $60 \%$ and personnel employment of over $80 \%$, they have already become to be the most active group for economic and social development in China, especially for its unique effect in constructing innovative nation from acceleration by scientific factors to driven by resources and factors has become to be the common view $[4,5]$. Scientific small micro-enterprise has become to the main force in economic development by its strong innovation motivation and flexible management mechanism, it is also the energetic strength for China to enhance self-innovation ability and establishment of innovation system. In the resources endowment of small micro-enterprise, tangible resource endowment such as flow asset, fixed asset etc, their effect on financing of small microenterprise it bigger than that of other resources endowment, although resources endowment such as technology, production and management ability, credit have started playing certain financing effect, which shows their financing state is developing towards better direction, this improvement is relatively limited, the traditional mortgages loan model has already loosened, which has improved effect for financing rights of small micro-enterprise. In aspect of financing right of small microenterprise, right reflection system can make small micro-enterprise obtain the most direct effect.

This paper uses scientific small micro-enterprise in Hebei as study background and makes resources integration in the process of development for enterprises in this province, constructs resources identification of scientific small micro-enterprise and overall structure of achievement mechanism, It makes discussion from aspects such as policy system, constriction system, operation mechanism and assessment mechanism, it analyzes how to construct resources and service platform system suitable for development state of Hebei small micro-enterprise.

\section{Analysis on Influence factors in Resources Integration of Hebei Scientific Small Micro- enterprise}

\subsection{Characteristics analysis on growth of Hebei scientific small micro-enterprise}

As it is indicated by diagram1, it is characteristics in the process of growth for Hebei scientific 
small micro-enterprise, it has the unique nature that some small enterprise dose not have, such as high risk, high growth, high innovation etc, which makes it different from other ordinary traditional enterprise, it obtains competitive advantage by innovating new products, new model, new technology or new service. Strengthen input strength in innovation fund, whether it can solve the development fund shortage for small micro-enterprise, which it becomes to be the important condition for it s survival and highs-speed growth. Because of the scale factor of small microenterprise, uncertainty of enterprise environment, innovation instability, it is easy to meet obstacle in the process of market promotion, product delay or listed speed may cause higher market risks. The success ratio of scientific small micro-enterprise is about $20 \%$. Once it is successful, innovation return will be 10 times even much more. Its development can indirectly increase scientific addedvalue of other industry products by correlation to the existing industry, promote technology updating of traditional industry, enhance production profit of the whole economic system, the position of small micro-enterprise becomes increasingly obvious in national economy, the role will become more and more important.

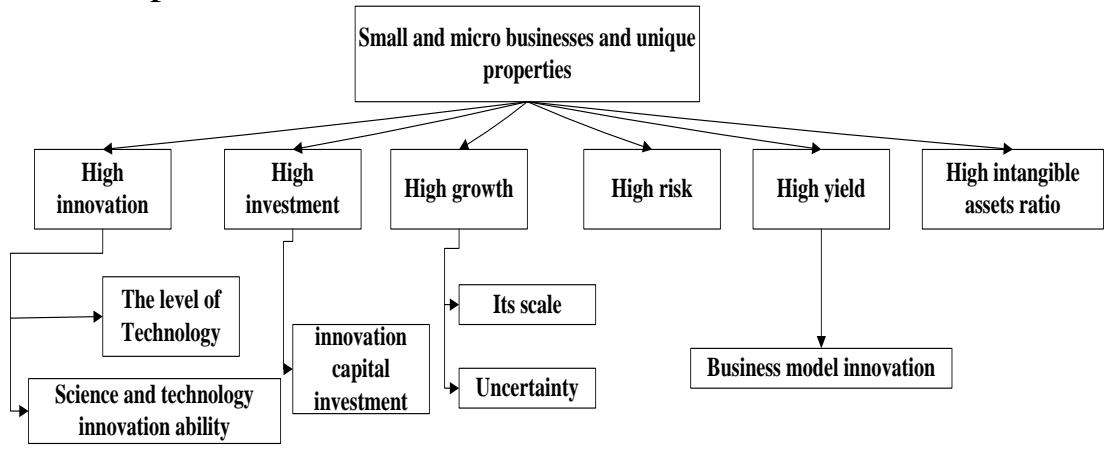

Diagram 1 Characteristics of Hebei scientific small micro-enterprise

\subsection{Factors of resources integration for scientific small micro-enterprise}

The main factors for enterprise growth lies in the external environment for enterprise survival and enterprise environment, as well as the key point of enterprise lies in superiority choice. Second is internal growth theory, such as resources theory, ability theory and knowledge theory, this kind of theory regard that the main important influence factors for enterprise growth derives from internal of enterprise, such as heterogeneity resources, core ability, implicit knowledge etc are the key for enterprise growth. The third is the integrating point of internal and external survival. 6 factors and analysis frame of scientific small micro-enterprise expect to provide basic theory base for policy formulation of small micro-enterprise in China. Analysis frame of 6 factors hat is growth motivation, opportunity base (policy environment, financing ecology), of which entrepreneur, technology innovation, financing ability, innovation network (it reflects ability of enterprise to obtain resources from outside) belong to internal growth factor, policy environment and law environment belong to external environment, which reflects external conditions of enterprise growth. Analysis on influence factors for enterprise growth and relations analysis on different influence factors are indicated by diagram2, theory model of influence factors on scientific small micro-enterprise in China.

Integration resources of Hebei science small micro-enterprise, in the following relation diagram, the bottom right policy, law environment and financial, ecological environment are the internal factors of affecting enterprise growth, which determines opportunity base for the development of scientific small micro-enterprise. Entrepreneur ability, financing ability and technology innovation are internal factors, regional innovation network in this study reflects ability of enterprise to obtain resources from network, so it belongs to the internal factors of enterprise, it reflects the initiative for enterprise to seek growth, its growth needs strong development motivation, entrepreneur ability can not do without the base to support enterprise growth, opportunity base(policy, law environment and financial, ecological environment) and resources base(financing ability)(internal resources) and regional innovation network(policy outsourcing), meanwhile it needs to have certain development 
ability(technology innovation). Under the combined effect of internal and external factor, it emerges the growth of scientific small micro-enterprise.

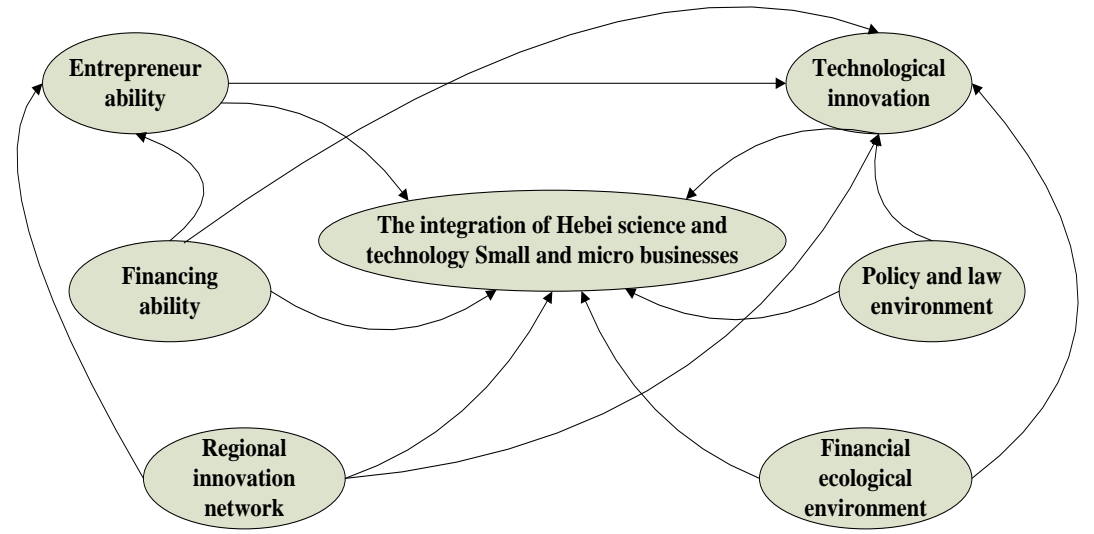

Diagram 2 Resources integration factor of Hebei scientific small micro-enterprise e

\section{Platform Model on Resources Integration of Hebei Scientific Small Micro-enterprise}

\subsection{Resources integration of scientific small micro-enterprise based on knowledge ontology}

It makes description for resources and it is stored in the computer, which convenient for users to check and search. At present, description on heterogeneous data universally adopts XML model, but it can not solve semantic isomerism. While knowledge ontology is standard description of sharing concept model, it can not use one kind of correct and format way to indicate regional knowledge, promote knowledge sharing, increase mutual operability of heterogeneous system. The ontology in this paper adopts OWL) Web Ontology Language) to make language description, the ontology model of partial ontology is indicated by diagram 3. The oval node represents category of OWL ontology, rectangular node represents the nature in OWL ontology. The link between oval and oval represents relations between categories, the link between oval and rectangular represents category of nature, which is type integer or string type.

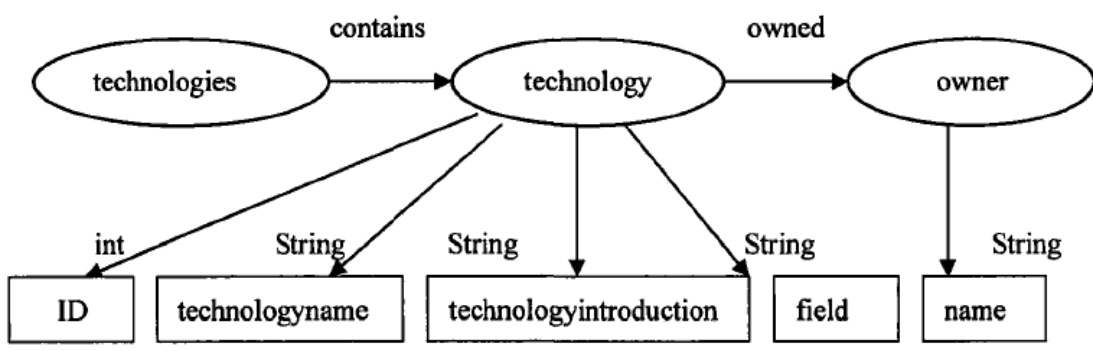

Diagram 3 Partial ontology model

It adopts PROMPT (Cruzl, 2004) method, it integrates the part established by the early paper and gets overall ontology GO, ontology model is indicated by diagram 4 . The category, nature and relations of overall ontology are combined by category, nature and relations in partial ontology L01, L02. Such as person is obtained by owner classification, it is the super class of owner. Partial ontology L01 and ontology L02 all appear class owner of concept equivalent owner, and address just appears for once, it is obtained by copying partial ontology. 


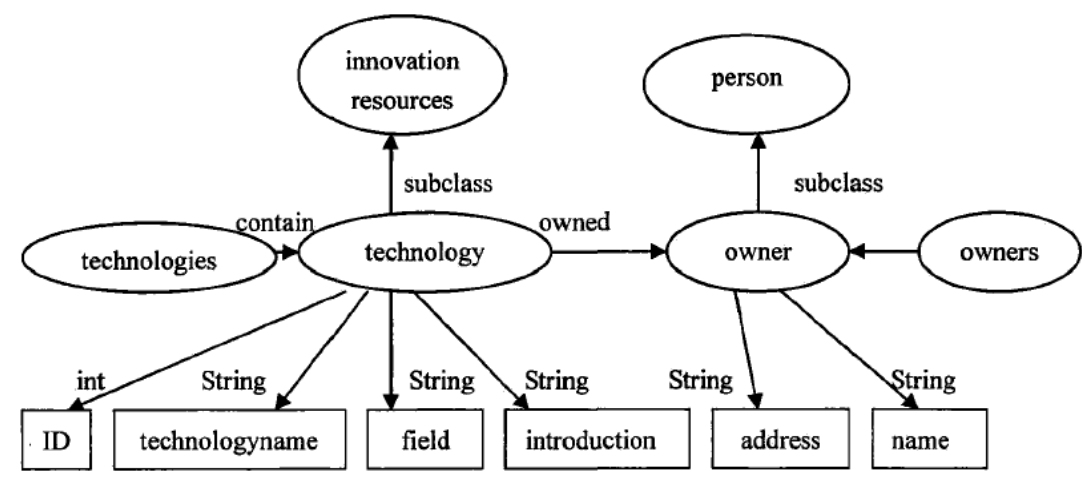

Diagram 4 Ontology model of overall ontology GO

\subsection{Organization structure of small micro-enterprise based on university resources model}

This paper combines with cloud commutating and Agent to establish platform and organization structure based on university resources, which is indicated by diagram 5 , the whole regional innovation platform is composed of 2 parts, the first part is service platform, including information integration platform of innovation resources and informatization service platform of the main innovation body. Information integration service platform of innovation resources is used to integrate and innovate all the necessary resources.

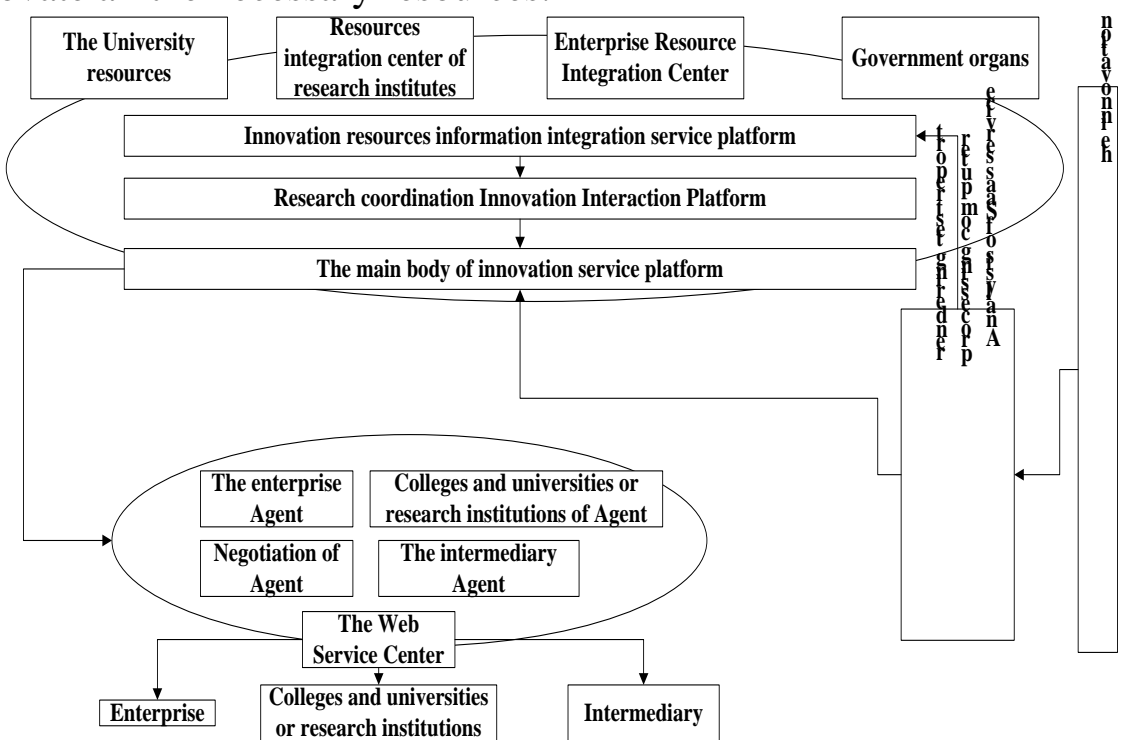

Diagram 5 Organization structure of regional coordinated innovation platform based on university resources

The establishment way of resources level can adopt model of cloud commutating. University, resources integration centres such as enterprise, science research department respectively corresponds to one private clod, and it is managed by each organization. Then it uses region as unit, private cloud internet and becomes to be regional cloud, the whole region is lead by government to establish one management commission to make comprehensive management.

\section{Demonstration Study and Resources Integration Measure of Hebei Small Micro-enterprise}

\subsection{Sampling enterprise choice and data analysis}

This paper adopts Tangshan scientific small micro-enterprise in Hebei, this area has formed entrepreneur population dare to establish business, be good at creation, brave of innovation and pleased to contribute. The understated and realistic tradition, which makes enterprise maintain lower asset-liability ratio, finance is relatively stable, self-capital is sufficient and anti-risk ability is stronger. Capital, brand consciousness, understated style, stable and perfect service has effectively prevented big change of enterprises. As for the data collected by questionnaire, this paper firstly 
establishes effective topic data base, and then it makes descriptive statistics analysis, validity and credit inspection, it makes model fitting and inspection on the basis of factor analysis, the software for statistics analysis is SPSS18.0 version and AMOS18.0 version, it adopts questionnaire to make data collection, in order to obtain reliable sample data and possibly reduce influence of external factors, this study makes direct interview and visit for distribution object, distribution channel and distribution area, it brings questionnaire to site to fill it and collect on site, it entrusts the third party such as government department and intermediary to make questionnaire distribution and collection.

\subsection{Measurement and variable of currency resources}

This paper adopts credit data, data of small enterprise, variables of Tangshan in Hebei from 2011 to 2014, they are as follows: financing amount of small enterprise(debt loan 1), financing amount 2 of small enterprise(flow debt loan 2), deposit balance(credit), medium and long-term loan (long), short-term loan (short), cash flow(curr) as panel data, it uses 2 kinds of financing amount to respectively construct 2 models to test effect of credit resources change on total financing and shortterm financing change of small enterprise, they are formula 1 and formula 2, it can get flexible parameter change value of small enterprise financing amount, that is formula 2 and formula 3 , model 3 and 4 include cash input variable, because cash input variable may be minus, and can not adopt logarithm, model 3 and 4 are flexible change value.

The basic form of model is as follows:

$$
\begin{aligned}
& \text { loan }_{i t}=\beta_{0}+\beta_{1} \text { credit }_{i t}+\beta_{2} \text { long }_{i t}+\beta_{3} \text { short }_{i t}+\beta_{4} \text { curr }_{i t}+\gamma_{1}+\gamma_{2}+\varepsilon_{i t} \\
& \text { loan }_{i t}=\beta_{0}+\beta_{1} \text { credit }_{i t}+\beta_{2} \text { long }_{i t}+\beta_{3} \text { short }_{i t}+\beta_{4} \text { curr }_{i t}+\gamma_{1}+\gamma_{2}+\varepsilon_{i t}
\end{aligned}
$$

$\mathrm{i} 、 \mathrm{t}$ respectively represents year, of which, $r_{1}, \gamma_{2}$ respectively represents observed factor relevant to year, $\varepsilon_{i t}$ represents random disturbance term. It can affect distribution of credit by credit policy such as loan deposit ratio, window instruction etc, credit resources will further affect financing procurability of small enterprise in space and time distribution, but credit policy can not be directly quantized, it can only use different credit resources supply as agent to observe change influence of credit policy.

\subsection{Structure change and result of debt}

Cash liabilities, growth decrease in debt makes it difficult for small enterprise to make financing, increase reduction in cash liabilities and debt (indicated by diagram 6), although debt causes certain debt burden for enterprises, it plays active financing effect, for example, small micro-enterprise plays credit effect on trust relations in the long-term market competition and cooperation, credibility is accumulated in the quick economic growth process, which can relieve financing difficulty for small enterprise, the accounts receivable, payable account even private credit loan cause prosperous economy and quick development in foreign trade. The financing environment faced by small microenterprise, it can rely on financing channel of irregular finance market, this it can produce much more credibility, it is the indication of cash liabilities and debt. 


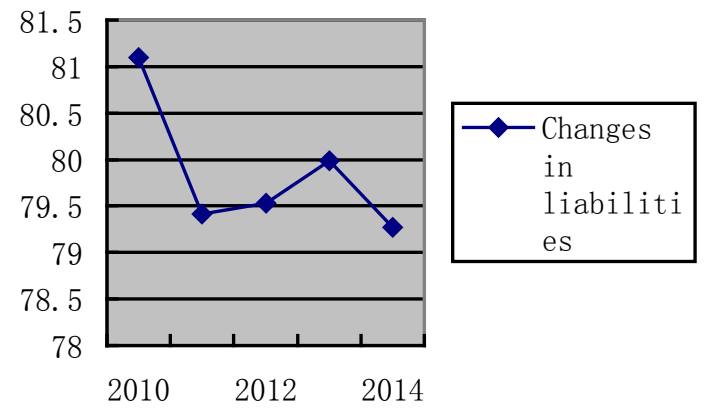

Diagram 6 Proportion of cash liabilities of small enterprises in debt

From the above we can find proportion of cash liabilities in small enterprise is gradually reducing, the decrease trend is not so obvious, but it can indicate that flowing environment that small enterprise in is becoming worse, some short-term loan have to be converted into long-term debt, the debt undertaken by small enterprise is aggravating, reduction in short-term loan will make capital turnover become much more difficult, some credits relied on for long time may become aggravated.

\subsection{Financing right of scientific small micro-enterprise under structure balance in currency market}

The fixed effect model indicates short-term loan and floating liabilities of small enterprise exists strong correlation, which shows that among credit re4sources, only space distribution of short-term loan has obvious effect on short-term financing of small enterprise, differences in short-term loan for difference provinces will also cause obvious difference in financing state of small enterprise, so it has important effect on financing of small micro-enterprise, credit policy and supervision policy should give proper inclination to short-term loan. The structure problem of currency resources in the financing market of small micro-enterprise is relatively serious. The balance of short-term loan in loan balance ratio decreases from $43.33 \%$ in 2010 to $36.86 \%$ of 2010 , there are scholars demonstrate the important effect of financial department, bank department matching with economic department. The distribution structure of credit resources dose not conform to financing demand of small micro-enterprise, it needs more short-term financing, the proportion reduction in short-term loan makes structure unbalance much more serious, so short-term loan has obvious effect on flow improvement for small micro-enterprise, Distribution proportion of short-term loan is small and tends to reduce, which makes flow improvement of small micro-enterprise become worse. The monopoly force in financial market aggravates this problem, difference in short-term loan in space distribution is very obvious, the model indicates stronger time effect, and time trend is obvious, this kind of structural problem will become worse as time goes by.

\section{Conclusions}

As for small micro-enterprise, the currency in currency market is very rich relatively to its financing demand, but unreasonable structure in currency market causes failure in financing right of small micro-enterprise and reduces its financing procurability, unreasonable distribution structure of credit resources is much more unfavourable for problem solution, obvious difference of shortterm loan in space distribution shows unfairness of credit resources in regional distribution, proportion in short-term loan and reasonable credit structure are the fundamental channel to improve financing stat of small micro-enterprise. We should reasonable enhance proportion of short-term loan in the whole credit resources so as to convert credit structure, make it conform to financing demand of small micro-enterprise, automatically increase currency flowing to small micro-enterprise by changing structure are the fundamental strategy of improving its financing state. 


\section{Acknowledgements}

The research work was supported by Hebei Planning Office of Philosophy and Social Science under Grant No. HB14GL058 and Ministry of Education of the People's Republic of China under Grant No.14YJC630044

\section{References}

[1] Chen Yongjun。Application of Law of Large Numbers in Small Macro-enterprise in Crediting Model [J].Financial Aspect, 2011,(12):49-52

[2] Zhuang Xintian, Huang Weiqiang. Study on Financial Innovation Poplarization Based on Consumer Network [J].Management Journal,2009,(6): 132 -140

[3] Pandza K, Thorpe R. Creative search and strategic sense-making: Missing dimensions in the concept of dynamic capabilities [J]. British Journal of Management, 2009, 20(s1): 118-131.

[4] Sun Yuewu, He Shizhong. Discussion on Technology Standard Cooperationand Cluster Virtualiation Development of Hi-tech Enterprises [J].Soft Science,2005, 19(5):78-81.

[5] Rhee J, Park T, Lee D H. Drivers of innovativeness and performance for innovative SMEs in South Korea: Mediation of learning orientation [J]. Technovation, 2010, 30(1): 65-75.

[6] Rush H, Bessant J, Hobday M. Assessing the technological capabilities of firms: Developing a policy tool [J]. R\&D Management, 2007, 37(3): 221-236.

[7] Sammarra A, Biggiero L. Heterogeneity and specificity of inter-firm knowledge flows in innovation networks [J]. Journal of Management Studies, 2008, 45(4): 800-829.

[8] Chilling M. A, Phelps C. C. Interfirm collaboration networks: The impact of large-scale network structure on firm innovation [J]. Management Science, 2007, 53(7): 1113-1126.

[9] Wan Guocai. Financing Channel and Demonstration Analysis of Small Micro-enterprise in Middle Area—Take Shiyan for example [J].Economy and Finance, 2010:90-95

[10] Teece, D.J. Explicating dynamic capabilities: The nature and microfoundations of (sustainable) enterprise performance [J]. Strategic Management Journal, 2007,28(13), 1319-1350. 